\title{
Correction: Correction to: A third representation of Feynman-Kac-Itô formula with singular magnetic vector potential
}

\section{Taro Murayama ${ }^{1}$}

Published online: 17 April 2021

(c) The Author(s), under exclusive licence to Springer Nature B.V. 2021

\section{Correction to: Letters in Mathematical Physics (2021) 111:33 https://doi.org/10.1007/s11005-021-01376-3}

The publication of this article unfortunately contained a mistake. In the last sentence before the Acknowledgements, $\mathrm{R}^{\mathrm{d}}$ must be changed into R. Please see below the corrected sentence:

Since $(0 \leq) \sup _{t \leq t^{\prime}}\left(\psi_{c, m}(T)(t)-\psi_{c, 0}(T)(t)\right) \rightarrow 0 \quad$ as $\quad m \downarrow 0 \quad v_{c, 0-\text { a.s. for any }}^{\Psi}$ $t^{\prime} \in[0, \infty)[14$, Proposition 4.2], the following convergence can be shown without $\operatorname{div} A \in L_{\text {loc }}^{1}\left(\mathbf{R}^{d} ; \mathbf{R}\right)$ by the Lebesgue dominated convergence theorem and the estimate (3.1) in Proposition 3.1:

[Theorem II] If $A \in L_{\text {loc }}^{2}\left(\mathbf{R}^{d} ; \mathbf{R}^{d}\right)$, then for a fixed $c>0, e^{-t \Psi_{c, m}\left(H_{A}\right)}$ converges to $e^{-t \Psi_{c, 0}\left(H_{A}\right)}$ in $L^{2}\left(\mathbf{R}^{d}\right)$ as $m \downarrow 0$, uniformly on every finite bounded interval in $t \geq 0$.

Publisher's Note Springer Nature remains neutral with regard to jurisdictional claims in published maps and institutional affiliations.

The original article can be found online at https://doi.org/10.1007/s11005-021-01376-3.

Taro Murayama

murayama@ishikawa-nct.ac.jp

1 Department of General Education, National Institute of Technology (KOSEN), Ishikawa

College, Kitachujo, Tsubata, Ishikawa 929-0392, Japan 